\title{
An improved K-means algorithm application in evaluating interactive mechanism of airline industry ecosystem stability
}

Qing Liu

Civil Aviation University of China, Tianjin 300300

China

liuqing@163.com

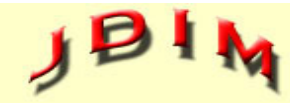

Journal of Digital Information Management
ABSTRACT: With the explosive growth of the mass data, the traditional architecture of the information system has been difficult to deal with enterprise needs. Data mining has become an important means of business innovation; it changed the development direction of cloud computing and also lead softwareas-a-service (SaaS) becomes the main indicator of the era of cloud 2.0. This paper proposed an improved Kmeans algorithm, and uses it to evaluate interactive mechanism of airline industry ecosystem stability. Aiming at the clustering instability problem of traditional $K$-means algorithm in the process of random selection, this paper proposes a stochastic selection method for clustering centers initialization, the efficiency of the algorithm also has been greatly improved. By using data mining method, we make analysis of the ecological stability system of aviation industry; the result shows that technological innovation is the source of system stability, so it is the key link to the stability of the industrial ecosystem.

Subject Categories and Descriptors

[H.2.8 Database Applications]; Data mining; [K.6.3 Software Management]: [H.3.4 Systems and Software]

\section{General Terms}

Software-as-a-service, Data Managment, Cloud Computing, K-Means Algorithm

Keywords: K-means algorithm, Data mining, Interactive mechanism, Airline industry

Received: 19 April 2017, Revised 28 May 2017, Accepted 5 June 2017
DOI: $10.6025 / \mathrm{jdim} / 2017 / 15 / 4 / 214-223$

\section{Introduction}

With the explosive growth of the mass data, based on the traditional architecture of the information system has been difficult to deal with; at the same time, the traditional business intelligence system and data analysis software, in the face of unstructured data in video, pictures, text and other data, but also the lack of effective analysis tools and methods [1]. Therefore, the urgent need to upgrade the information system is facing the urgent need for the information industry to bring new, broader growth point. Such as large data for efficient storage, real-time analysis challenges the on chip, the storage industry produced important influence, promote the integration of the data storage and processing server, memory computing products upgrading and innovation; the data fast processing and the analysis of demand, will promote business intelligence and data mining software in enterprise information system integration application, has become an important means of business innovation; the rise of large data processing also changed the development direction of cloud computing and make it into the analysis as a service (SaaS) as the main indicator of the era of Cloud 2.0. In the foreseeable future, new products, new technologies, new services, new formats for the big data market will continue to emerge[2-3].

Distributed data mining is used to solve the problem of data mining in homogeneous or heterogeneous data sources. And parallel processing technology, which makes it very good to deal with the scalability problem in the process of mining. It has been shown to have very good efficiency in the distributed application environment. 
Compared to centralized data mining, distributed data mining has a very good privacy protection. In practical applications, due to privacy or legal considerations, a lot of data is not suitable for centralized analysis. The use of distributed data mining, you can use the computing resources of each node. Nodes will process the data and transmit the intermediate results, not all of the data, so that it is natural to protect the privacy of the data. In addition, the distributed data mining system will be deployed in large scale server cluster, using software instead of hardware to ensure the stability of the system, thus reducing the cost of the entire system. Clustering is based on the characteristics of the data set; the data are divided into different categories. Its goal is to make the data within the same class have a high degree of similarity, and the different classes have nothing to do, and clustering is an unsupervised learning method. Among them, the Kmeans algorithm is a classical clustering algorithm because of its simple and efficient characteristics of a wide range of attention and research. In recent years, a large number of research results have emerged on the Kmeans algorithm, including the improvement of the efficiency of the algorithm and the optimization of the parallel system.

This paper research on an improved K-means algorithm application, and then evaluates interactive mechanism of airline industry ecosystem stability. As a practical tool to realize sustainable development, industrial ecosystem has been rapidly popularized in the world[4]. Some developed countries, such as Denmark, the United States and Canada began very early planning and construction to build eco industrial system is the main content of the eco industrial demonstration park, other countries such as Thailand, Indonesia, the Philippines and other developing countries are also actively build eco industrial park[5-6]. China in 1999 to start the construction of eco industrial demonstration park, according to statistics, by the end of April 2011, Ministry of environmental protection and the national eco industrial demonstration park construction leading group approved a total of 54 Industrial Park to carry out the national eco industrial demonstration park construction, local students state industrial park of more than 300 . However, with the rapid expansion of the scale of the industrial ecosystem practice, many problems have gradually emerged in the actual operation process, and the stability problem is the most outstanding one. Includes world public recommendation for example Kalundborg symbiosis, some eco industry system in the process of operation has appeared ecological industrial chain fracture, change, even to collapse of the whole system. In view of this, the in-depth study of the stability of the industrial ecosystem is essential to maintain its good operation and to achieve success [7]. Among them, the research on the mechanism of influencing factors is the premise and foundation of the research on the stability of industrial ecosystem[8].

\section{Data mining}

Data mining is a large number of relevant data base on the data to explore and establish a model of advanced methods, the data source if the massive, real, and real data most of all there is noisy or missing; users are interested in and required knowledge is certainly can be mined; the discovered knowledge for decision maker is service, so it is acceptable, easy to understand, can be widely applied, and can solve some of the problems found. The research of data mining technology is integrated with the technology of multi subject intersection, which makes the data mining technology presents a variety of forms. Any method has its application field, at the same time; any kind of method is not a panacea, it is impossible to solve all kinds of problems. Mature data mining system should integrate many kinds of mining methods; analyze data from many angles, in order to make up the deficiency of single data mining method.

- Artificial neural network method: Neural network in recent years by the people's attention, due to its own has good robustness, self-organization, adaptive, parallel processing, distributed storage and high fault tolerance and other characteristics, processing complexity problem provides relatively effective and simple method. It is modeled on the structure and function of human neurons, which can be used to generate patterns for prediction and classification. It establishes three kinds of neural network models, which are based on the MP model and the Hebb learning rule.

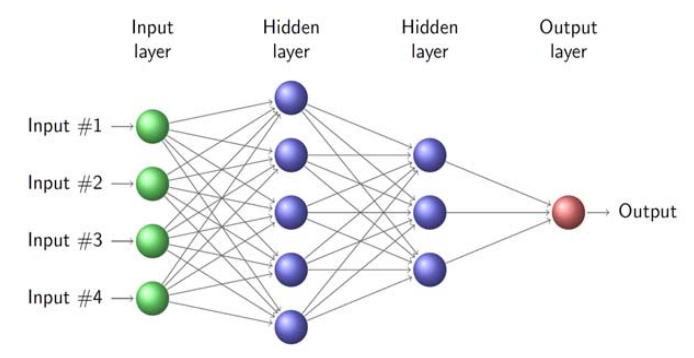

Figure 1. Artificial neural network

- $\square$ Cluster analysis: Clustering analysis is mainly study in accordance with the "Like attracts like." thought, is a non-supervised learning method. To the large set of data points designated cut into several groups (or classes), makes the data in each group between the high degrees of similar, the distance between possible small; and in different group data with a high degree of dissimilarity between distances as far as possible to large. Clustering analysis method is widely used in the field of classification, clustering in biology through the derivation of the classification of plants and animals, according to the similarity function of genetic gene classification, so as to get the inherent structure of the population. In business, clustering can help market analysts to find some rules from the base of the consumer buying patterns.

Decision tree method: The decision tree method is a common prediction modeling method for classification, 
clustering and prediction, it mainly uses the idea of divide and conquers, and the first problem search space is divided into several parts, and then is processed sequentially. Therefore, the decision tree to establish the growth process is actually the process of data rules generation. Decision tree method is simple and fast, it is very suitable to deal with non-numerical data, it is easy to visualize the data into a rule.

- Association rules: The main technology of the association analysis is the association rules, which is one of the main research fields of data mining and one of the mature technologies. It can identify the relationship between the data items in a given data set and structure characteristics, and describe the relationship between the data items. In the retail industry and related technology can help the operator found that consumers buy hobby, an accurate description of characteristics of consumers and to provide consumers with the purchase; can help to analyze the consumer cycle time, reasonable arrangements for inventory and purchase.

Data mining generally through data preparation, data mining, the results of expression and interpretation of the three stages, it is a forward, and complete the learning process. The following figure 2 shows data mining process shows the process of mining previously unknown, valid, and available information from the mass of data to form the knowledge.

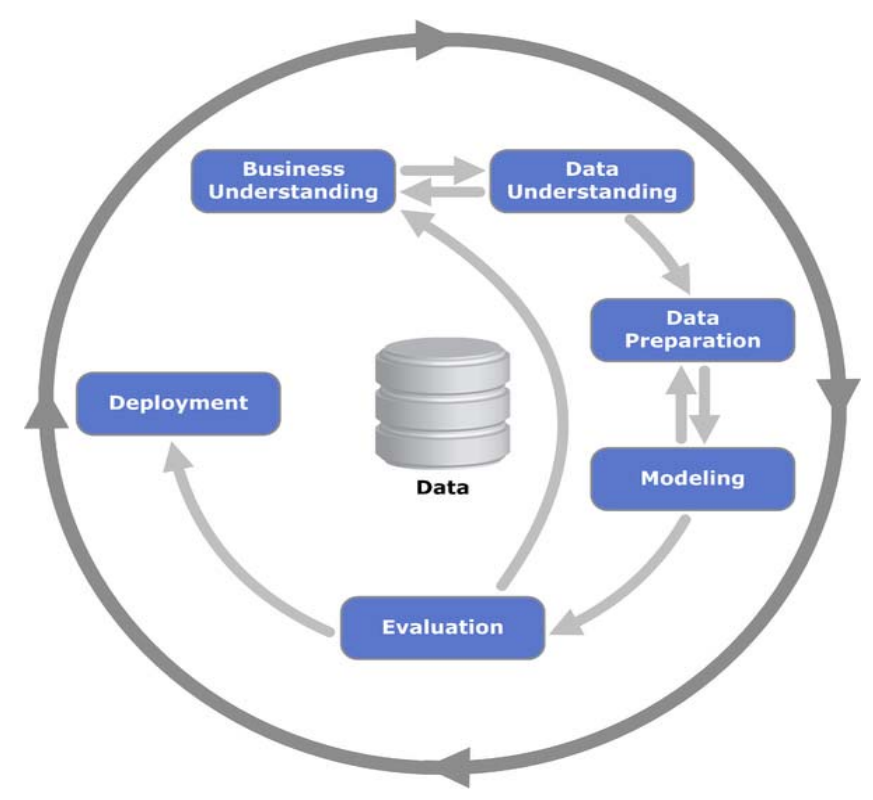

Figure 2. Data mining process

The basic idea of ID3 algorithm is that the attribute selection metric is used to select the best attribute as the node. The greater the value of the information gain, the smaller the uncertainty, so that when the test of each non leaf node, can get the maximum number of categories of information being tested. The desired information for the classification of a given training data is given by the following formula:

$$
\operatorname{Info}(D)=-\sum_{i=1}^{m} p_{i} \log _{2}\left(p_{i}\right)
$$

Suppose that the tuple in $D$ is divided into $A$ according to the attribute $\mathrm{V}$, in which the attribute $\mathrm{A}$ can be measured by the following formula, according to the observation of the training data:

$$
\operatorname{Info}(A)=\sum_{j=1}^{v} \frac{\left|D_{j}\right|}{|D|} \operatorname{Info}\left(D_{j}\right)
$$

The information gain to be obtained from the branch on the attribute $A$ can be described as:

$$
\operatorname{Gain}(A)=\operatorname{Info}(D)-\operatorname{Info}(A)
$$

ID3 algorithm has its advantages as follows: the basic principle of the algorithm is clear; the classification speed is fast; the practical value of the sample learning algorithm. C4. 5 algorithm is an extension of ID3 algorithm, an early machine learning algorithm, it is also a common algorithm to construct decision tree classifier, which is the basis of many decision tree algorithms. Information gain rate (ratio gain) as an extension of the information gain, to solve the problem of ID3 shortcomings. The segmentation information is defined as follows:

$$
\operatorname{SplitInfo}(A)=-\sum_{j=1}^{y} \frac{\left|D_{j}\right|}{|D|} \times \log _{2}\left(\frac{\left|D_{j}\right|}{|D|}\right)
$$

Information gain ratio equals the ratio of information gain to segment information:

$$
\operatorname{GainRatio}(A)=\operatorname{Gain}(A) / \operatorname{SplitInfo}(A)
$$

Classification and regression tree is a technique to create a binary decision tree, cart algorithm to Gini coefficient and variance based selection optimal grouping variables and split point, from selected Gini coefficient is the minimum value of the property as the test attribute, if the smaller the Gini coefficient, divided more reasonable, purity of the sample set higher. If the training tuple set $D$ contains a record of the $\mathrm{M}$ category, then the Gini refers to the calibration:

$$
\operatorname{Gini}(D)=1-\sum_{i=1}^{m} p_{i}^{2}
$$

If $D$ is divided into two parts, $D 1$ and $D 2$, the Gini coefficient of the division is

$$
\operatorname{Gini}(D)=\frac{\left|D_{1}\right|}{|D|} \operatorname{Gini}\left(D_{1}\right)+\frac{\left|D_{2}\right|}{|D|} \operatorname{Gini}\left(D_{2}\right)
$$




\section{Improved K-means algorithm}

\subsection{K-means++ algorithm}

Compared with the classical algorithm, the K-means++ algorithm is different from the initialization strategy. Algorithm from the data set of random selection of the first center, and the rest of the central point is through the probability to filter; the probability is proportional to the distance between the node and the initial center. The pseudo code of the algorithm is as follows:

\section{Algorithm 1: K-means++ \\ Input: $\mathrm{k}, \mathrm{X}=\{\mathrm{x} 1, \mathrm{x} 2, \mathrm{x} 3, \mathrm{xn}\}$ \\ Output:C $=\{\mathrm{c} 1, \mathrm{c} 2, \mathrm{c} 3, \mathrm{cn}\}$}

Step1: $\mathrm{C} \leftarrow 0$

Step2: Randomly selected from the collection node $\mathrm{x}$ as the first initial node $\mathrm{C}=\mathrm{C} \cup\{\mathrm{x}\}$

Step3: while $(|\mathrm{C}|<\mathrm{k}) \mathrm{do}$

Step4: Traversal $\mathrm{x} \in \mathrm{X}$, select the node as a new initialization center. $\mathrm{C}=\mathrm{C} \cup\{\mathrm{x}\}$

Step5: end while, $|\mathrm{C}|=\mathrm{k}$.

Step6: The element in the set $\mathrm{C}$ is used as the initialization center node,Lloyd's iteration according to the standard K-means algorithm, until convergence of the algorithm

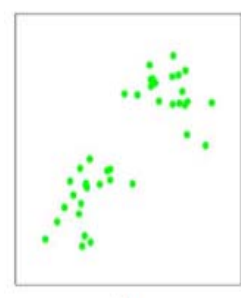

(a)

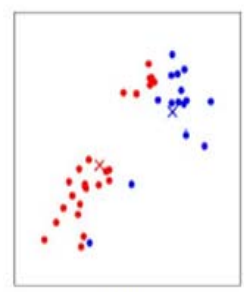

(d)

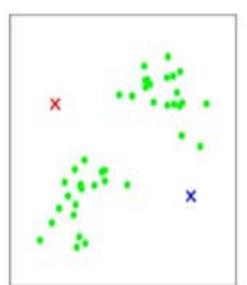

(b)

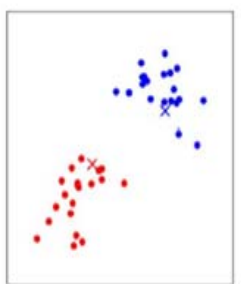

(e)

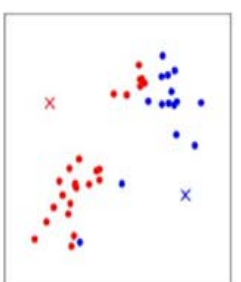

(c)

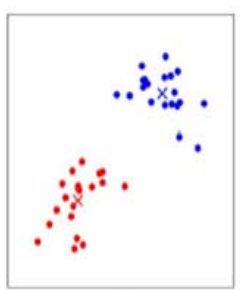

(f)
Figure 3. Algorithm solving process

The algorithm makes use of such an intuitive fact: a good clustering algorithm, the cluster should be relatively dispersed. So in choosing a new cluster center should be as far as possible to choose from the other center of the node. Both in theory and in engineering practice, $\mathrm{K}$ means++ has been proved to be far superior to the classic K-means. Although K-means++ algorithm has achieved great efficiency, but it also has shortcomings, limiting its application, that is, the inherent nature of the algorithm. When the input data set for the $\mathrm{D}$ dimension, the size as $\mathrm{n}$, the number of clusters for $\mathrm{K}$, the total running time of the algorithm is $\mathrm{O}(\mathrm{nkD})$, which is similar to the time spent on a single s' Lloyd iteration. In spite of this, the algorithm can not be implemented in parallel. In the initializa- tion, a node can is chosen to be the probability of the $i$-th center depends entirely on before II a center of the selection. The implementation of the original K-means++ algorithm, can only run on a single machine, scanning the local all the data to generate the initial center. When dealing with massive data, this limit is even more serious. First, with the growth of the data set, the number of categories will increase. For example, in a typical case, the algorithm has to scan all the data at once to complete the initialization action by integrating the millions of nodes into 100 or 1000 clusters. If the residual algorithm steps (such as Lloyd 's iterative process) can through parallel implementation, such as MapReduce to improve running speed, then initialize spent time will become performance bottlenecks in the clustering process. So in a lot of applications, the researchers used similar K-means++ other initialization algorithm, they can achieve efficient parallel. In addition, in the K-meas++ algorithm, the Euclidean distance is still used to calculate the distance of each data node to the center point. In the calculation process, the different attributes of the node are treated specially. However, in practical applications, some of the attributes must have a greater impact on the clustering results, and some of the properties are weak.

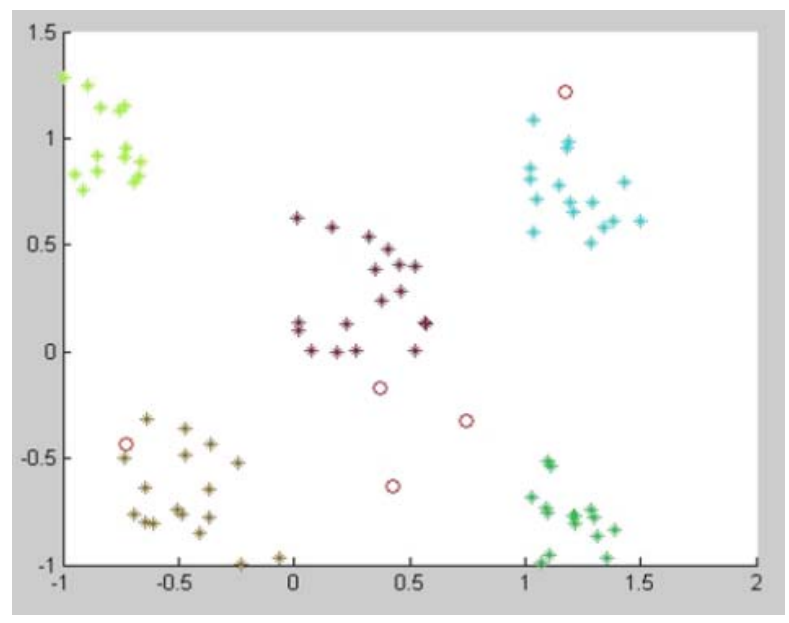

Figure 4. K-means initial point selection

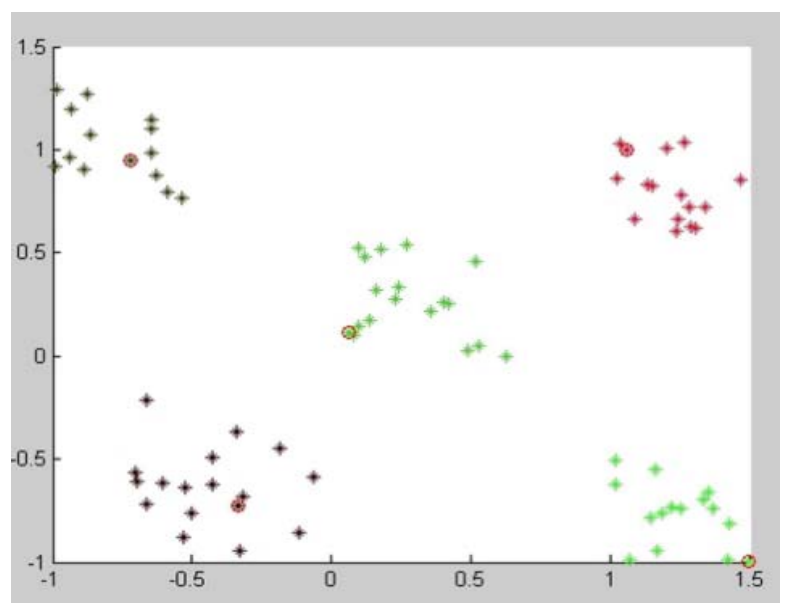

Figure 5. Initial point selection of k-means++ algorithm 


\subsection{Improved algorithm}

Attribute weight is the influence degree of the clustering result. If the weight is large, the influence of the attribute to the clustering result is bigger. This is more in line with the practical application of the situation. In order to calculate the attribute weights, the concept of information entropy is introduced. The information entropy to represent objects contained in the amount of information, entropy is small, is included in the greater the amount of information, distribution to the weights of the attributes should also bigger. Conversely, the smaller the amount of information, the smaller the value should be. An input data set contains $\mathrm{n}$ number as $\mathrm{m}$ dimensional objects, the input data can be represented as follows.

$$
X=\left|\begin{array}{cccc}
x_{11} & x_{12} & \cdots & x_{1 m} \\
x_{21} & x_{22} & \cdots & x_{2 m} \\
\vdots & \vdots & \vdots & \vdots \\
x_{n 1} & x_{n 1} & \cdots & x_{n m}
\end{array}\right|
$$

In order to calculate the attribute entropy and need with different dimension attribute values can be compared with the various properties of 0-1 standardization:

$$
b_{i j}=x_{i j} / \sum_{i=1}^{n} x_{i j}
$$

We can get the attribute weight matrix $B$

$$
B=\left|\begin{array}{cccc}
b_{11} & b_{12} & \cdots & b_{1 m} \\
b_{21} & b_{22} & \cdots & b_{2 m} \\
\vdots & \vdots & \vdots & \vdots \\
b_{n 1} & b_{n 1} & \cdots & b_{n m}
\end{array}\right|
$$

The information entropy of the calculation of the j dimension attribute

$$
s_{j}=-p \sum_{i=1}^{n} b_{i j} \ln b_{i j}
$$

Calculate the difference value of the $\mathrm{j}$ dimension attribute

$$
c_{j}=1-s_{j}
$$

The difference value indicates the influence degree of the attribute to the clustering result, when the difference value is $\mathrm{Cj}$ issmaller, then the $\mathrm{Sj}$ is bigger, and the influence degree of the attribute to the clustering result is smaller.Calculate the weight of the $\mathrm{j}$ dimension attribute:

$$
w_{j}=\frac{c_{j}}{\sum_{j=1}^{m} c_{j}}
$$

The weighted Euclidean distance formula of the object is expressed as:

$$
d\left(x_{i}, x_{k}\right)=\sqrt{\sum_{j=1}^{m} w_{j}\left(x_{i j}-x_{k j}\right)^{2}}
$$

By multiplying the weights in the formula, we can describe the contribution of the attributes to the distance between the objects. The greater the attribute value, the greater the contribution, which is more in line with the actual application situation.

\section{Industry ecosystem stability system}

Industrial ecosystem is a complex system, which can be regarded as a highly coordinated system composed of four subsystems, which are interrelated, interactive, interdependent society, resources, environment and economy. The social subsystem is mainly refers to the system between the various enterprises related activities; resources resources subsystem is generalized resources, in addition to natural resources, including technology and other resources; environment subsystem is refers to the external environment of industrial ecological system, such as the policy of the government and public pressure, economic subsystem is economic factors that influence the development of the system, such as assets, transaction costs.

\section{1 influence factors}

The influence factors of the stability of industrial ecosystem are a relatively concentrated area of stability research. Domestic and foreign research data show that there are many factors that affect the stability of industrial ecosystem involved, such as the mutual degree of dependence among the members, member distance, various members of the industry, industry ecosystem geography position, keystone species ecological chain enterprises and length, and so on. Generally speaking, the influence factors of the stability of the industrial ecosystem can be summarized as the structure dimension, the technical dimension, the external condition dimension and the economic dimension.

The above research results provide a good foundation for the further study of the stable operation mechanism of industrial ecosystem. But is worth pointing out, these factors are not alone, and is often constitute a dynamic system, and in time and space under the joint action of the development and evolution of eco industrial system impact. That is to say, all the factors which affect the constitute the complex nonlinear dynamic feedback system. At present, the research of this angle is not much, so it is urgent to strengthen. Therefore, this thesis will base on the ideas of system dynamics. Analysis the relationship structure between the key influence factors, and the key factor variables directly or indirectly for the stability of the system of the path, so as to find out the 


\begin{tabular}{|c|c|c|}
\hline Dimension & Influence factor & Main point \\
\hline \multirow{6}{*}{$\begin{array}{l}\text { Structure } \\
\text { dimension }\end{array}$} & $\begin{array}{l}\text { geographical } \\
\text { position }\end{array}$ & $\begin{array}{l}\text { The location of the location for investment, access to good human resources and } \\
\text { other supporting role is very significant }\end{array}$ \\
\hline & Member distance & $\begin{array}{l}\text { The localization of the system within the system has a huge impact on the operation } \\
\text { of the system }\end{array}$ \\
\hline & Core members & $\begin{array}{l}\text { Key kinds of enterprises play a key and important role in the construction of } \\
\text { enterprise symbiosis and the stability of eco industrial system }\end{array}$ \\
\hline & $\begin{array}{l}\text { Ecological chain } \\
\text { length }\end{array}$ & The length of the ecological chain, directly affects the stability of the system \\
\hline & Industry diversity & $\begin{array}{l}\text { Members of the organization of diversity is maintained by the premise of the } \\
\text { stability of industrial ecosystem }\end{array}$ \\
\hline & $\begin{array}{l}\text { Mutual } \\
\text { dependency }\end{array}$ & $\begin{array}{l}\text { Ecosystem stability largely depends on the species within the system of mutual } \\
\text { connection degree (relational) }\end{array}$ \\
\hline \multirow{4}{*}{$\begin{array}{l}\text { Technology } \\
\text { dimension }\end{array}$} & $\begin{array}{l}\text { Adequate } \\
\text { technology }\end{array}$ & $\begin{array}{l}\text { Divide the ecological engineering technology and traditional engineering caused by } \\
\text { ecological technical barriers to implementation }\end{array}$ \\
\hline & $\begin{array}{l}\text { technological } \\
\text { innovation }\end{array}$ & $\begin{array}{l}\text { Ecological enterprise technology is highly embedded in the production process of } \\
\text { the mature technology }\end{array}$ \\
\hline & $\begin{array}{l}\text { Information } \\
\text { exchange platform }\end{array}$ & $\begin{array}{l}\text { Due to the difficult to meet the requirements of decision support, the slow progress } \\
\text { of the industrial ecosystem [19]; information sharing efficiency will reduce the } \\
\text { stability of industrial ecosystem symbiotic network }\end{array}$ \\
\hline & Technical barrier & $\begin{array}{l}\text { The company held a confidential attitude to its waste, in case of competitors by its } \\
\text { vice products speculated that the relevant business opportunities confidential }\end{array}$ \\
\hline \multirow{6}{*}{$\begin{array}{l}\text { External } \\
\text { condition } \\
\text { dimension }\end{array}$} & $\begin{array}{l}\text { Government } \\
\text { support }\end{array}$ & $\begin{array}{l}\text { Holland's industrial ecosystem than the United States in the operation of the } \\
\text { process is more stable because of government intervention less }\end{array}$ \\
\hline & Market changes & $\begin{array}{l}\text { As a special enterprise alliance, the operation process of the industrial ecosystem } \\
\text { is greatly influenced by the supply and demand of the market }\end{array}$ \\
\hline & $\begin{array}{l}\text { New energy and } \\
\text { new materials }\end{array}$ & $\begin{array}{l}\text { The emergence of new energy and new materials is likely to lead to the rapid } \\
\text { collapse of the current stable closed-loop flow of industrial ecosystems }\end{array}$ \\
\hline & Public pressure & $\begin{array}{l}\text { Public demand for environmental conditions and ecological protection may make } \\
\text { the industrial ecosystem in a relatively stable state }\end{array}$ \\
\hline & legal system & $\begin{array}{l}\text { Once a substance is confirmed into toxic waste, the recycling system facing } \\
\text { challenges will be very strict, supply of raw materials for industrial ecosystem } \\
\text { will change }\end{array}$ \\
\hline & Economic support & $\begin{array}{l}\text { effective economic support can reduce the cost of capital construction, while easing } \\
\text { the financial pressure and the underwriting of securities }\end{array}$ \\
\hline \multirow{6}{*}{$\begin{array}{l}\text { Economic } \\
\text { dimension }\end{array}$} & Search cost & $\begin{array}{l}\text { To build a symbiotic relationship requires a lot of time, manpower and financial } \\
\text { resources to search for relevant information. }\end{array}$ \\
\hline & Negotiation cost & $\begin{array}{l}\text { Negotiation cost is an important factor that cannot be ignored in the process } \\
\text { of establishing the symbiotic relationship between enterprises. }\end{array}$ \\
\hline & executory costs & $\begin{array}{l}\text { Participation in the symbiotic enterprise, can fulfill the contract there is a certain risk, } \\
\text { the enterprise must take appropriate measures to implement the contract, is bound } \\
\text { to increase transaction costs }\end{array}$ \\
\hline & Risk cost & $\begin{array}{l}\text { Potential risks are likely to bring a very large transaction costs to the } \\
\text { symbiotic enterprises. }\end{array}$ \\
\hline & Asset specificity & $\begin{array}{l}\text { Asset specificity is the degree of difficulty in re allocation of assets which have } \\
\text { already been put into production. }\end{array}$ \\
\hline & Other costs & Transaction costs caused by unpredictable factors \\
\hline
\end{tabular}

Table 1. Factors affecting the stability of industrial ecosystem 
interaction mechanism between the influencing factor variable and the stability of the system variables and feedback relationships, and are given on the basis of this enhanced the stability of industrial ecosystem's suggestions.

\subsection{The system model construction of the influence factors on the stability of the social subsystem}

In the social system, the main factors affecting the stability of the industrial ecosystem with geographical location, key enterprises, the member of the system between the distance and ecological chain length, industry diversity of structure dimension factors. These influencing factors interact with each other and their path to stability:

(1) System stability $\square+$ Geographical position $\square+$ Key enterprises $\square+$ Ecological chain length $\square+$ industry diversity $\square+$ System stability

Show that: with the enhancement of the stability of the system, the superiority of the system in which the location will be enhanced, which further enhance the comprehensive strength of the key enterprises, which will attract more enterprises to actively join the industry chain, increase the ecological chain, and increases the diversity of industry, can improve the system's resilience, and enhance the system's ability to adapt, and ultimately makes the system stability is further enhanced.

(2) System stability $\square+$ Geographical position $\square+$ Key enterprises $\square+$ Ecological chain length $\square+$ industry diversity? $\square$-degree of mutual dependence $\square$-System stability

Show that: with the enhancement of the stability of the system, the superiority of the system in which the location will be enhanced, which further enhance the comprehensive strength of the key enterprises, which will attract more and more enterprises to actively join the industry chain, increased the length of the ecological chain, and increases the diversity of industry, industry at the same time diversity of the increase will lead to some enterprises between the degree of interdependence in the weakened, and the stability of the system greatly and depends on the degree of interdependence in the internal system, therefore, depend on the degree of weakening, may hinder the steady development of the system.

(3) System stability $\square+$ Geographical position $\square+$ Key enterprises $\square+$ Ecological chain length $\square+$ industry diversity $\square$-degree of mutual dependence $\square+$ System stability

Show that: with the enhancement of the stability of the system, the superiority of the system in which the location will be enhanced, which further enhance the comprehensive strength of the key enterprises, which will attract more and more enterprises actively join the industry chain, increase the ecological chain, and increases the diversity of industry, and Industry diversity of increase will lead to some enterprises between the degree of interdependence in the weakened. And dependence among enterprises if too large, pose a risk, if some enterprises in the industrial chain of technological innovation will inevitably makes the dependence degree of the enterprise turmoil, which greatly increases the risk of the system, and even can cause the industrial chain fracture. Therefore, from the perspective of analysis, interdependence degree of enhancement and weaken the system's stability.

(4) System stability $\square+$ Geographical position $\square+$ Key enterprises $\square+$ Ecological chain length $\square+$ Member distance $\square+$ Member exchange barriers $\square$-System stability

Show that: with the enhancement of the stability of the system, the superiority of the system in which the location will be enhanced, which further enhance the comprehensive strength of the key enterprises, which will attract more enterprises to actively join the industry chain, increase the ecological chain, but it will lead to the increase of the geographical distance between the members, makes members of communication barriers increase, and ultimately increase the system stability. According to the above analysis, (1) (3) means the positive and negative feedback loop,(2) (4) is the negative feedback loop to reduce the stability of the industrial ecosystem. Based on the above analysis of the stability of the industrial ecosystem and its social subsystem, the mechanism of the influence factors are as follows:

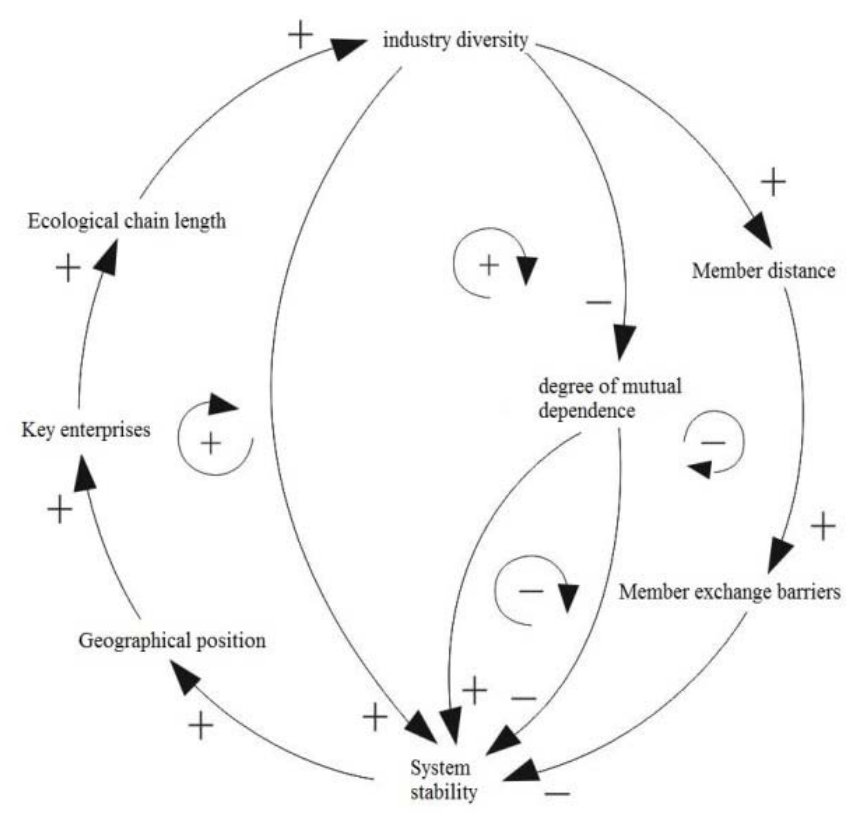

Figure 6. The function mechanism of the industrial ecosystem stability in the social subsystem

\subsection{The factors affecting the stability of the resource subsystem}

In the resource subsystem, the main factors affecting the stability of the industrial ecosystem are technological innovation, technical adequacy, technical rigidity and other 
factors. These influencing factors interact with each other and their path to stability:

(1) System stability $\square+$ technical innovation $\square+$ technical adequacy $\square+$ system stability

It shows that the enhancement of system stability will reduce the opportunity cost of technological innovation, which can promote the technological innovation of the system, which will bring about the ecological technology needed by the system to enhance the stability of the system.

(2) System stability $\square+$ technical innovation $\square+$ asset specificity $\square+$ Interdependent degree $\square+$ system stability It shows that despite the system stability enhancement can promote technology innovation, but innovation needs more capital investment, improve asset specificity, which makes members in the system of interdependence increased, thereby increasing the system stability

(3) System stability $\square+$ technical innovation $\square+$ asset specificity $\square+$ Interdependent degree $\square$-system stability

It shows that despite the system stability enhancement can promote technology innovation, but innovation need more capital investment, increase the asset specificity, which makes members in the system of interdependence increased, and if the enterprise rely too much, the greater the risk may eventually reduce system stability.

According to the above analysis, (1) (3) is the positive and negative feedback loop for the stability enhancement of the industrial ecosystem (2) is the negative feedback loop to reduce the stability of the system. Based on the above analysis, the mechanism of the influence factors of the stability of the industrial ecosystem and its resources subsystem is shown as follows:

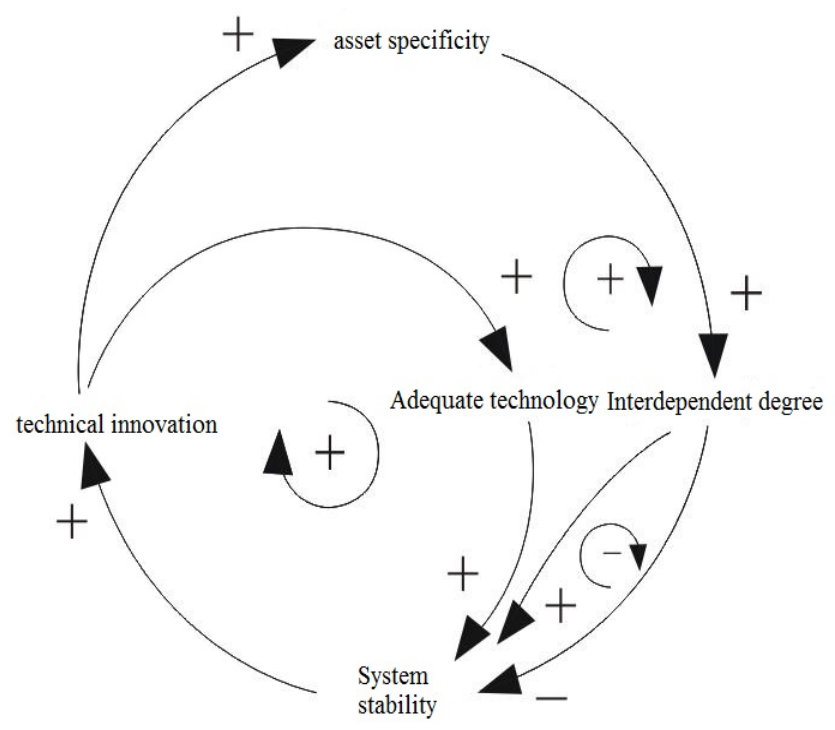

Figure 7. Industrial ecological system stability in the resources subsystem
4.4 The system model construction of the influence factors on the stability of the environment subsystem In the environment subsystem, the main factors that affect the industrial ecosystem are government support, market changes, public pressure, legal system, economic support, environmental improvement and other external factors. These influencing factors interact with each other and their path to stability:

(1) System stability $\square+$ government support $\square+$ policy system $\square+$ +economic support $\square$ - market changes?+system stability

Show that the system operation more stable, government's attitudes on the development of industrial ecological system will more optimistic, support will increase, to eco industrial development policy system will gradually improve, to efforts to support the economy will be enhanced. As a result, the enterprise on the market negative change in reduced sensitivity, by the market environment changes impact to the development of the system will be eased, so as to enhance the stability of a system.

(2) System stability $\square+$ government support $\square+$ policy system $\square$ +legal system $\square$-system stability

Show that with the stable operation of the system, increase government support system of ecological industry, policy system which is beneficial for the development of ecological industry gradually perfect, and for certain toxic substances and waste type enterprises and puts forward the legal system also in gradually perfect, system in the industrial chain can thus fracture occurs, it will directly impede the stable development of the system.

(3) System stability $\square+$ government support $\square+$ policy system $\square+$ economic support $\square+$ environment improvement $\square+$ system stability

Show that with the stable operation of the system, increase government support system of ecological industry, policy system which is beneficial for the development of ecological industry gradually improve and related fields of economic support efforts to increase and the legal system improvement to create a promote eco industrial development of public opinion and social environment, so as to promote the stable development of the system.

According to the above analysis, (1) (3) the positive and negative feedback loop for the stability enhancement of the industrial ecosystem (2) is the negative feedback loop to reduce the stability of the system. Based on the above analysis, the mechanism of the industrial ecosystem stability and its influence factors in the environment subsystem is shown as follows:

4.5 Mechanism model of comprehensive action According to the influence on the stability of industrial 


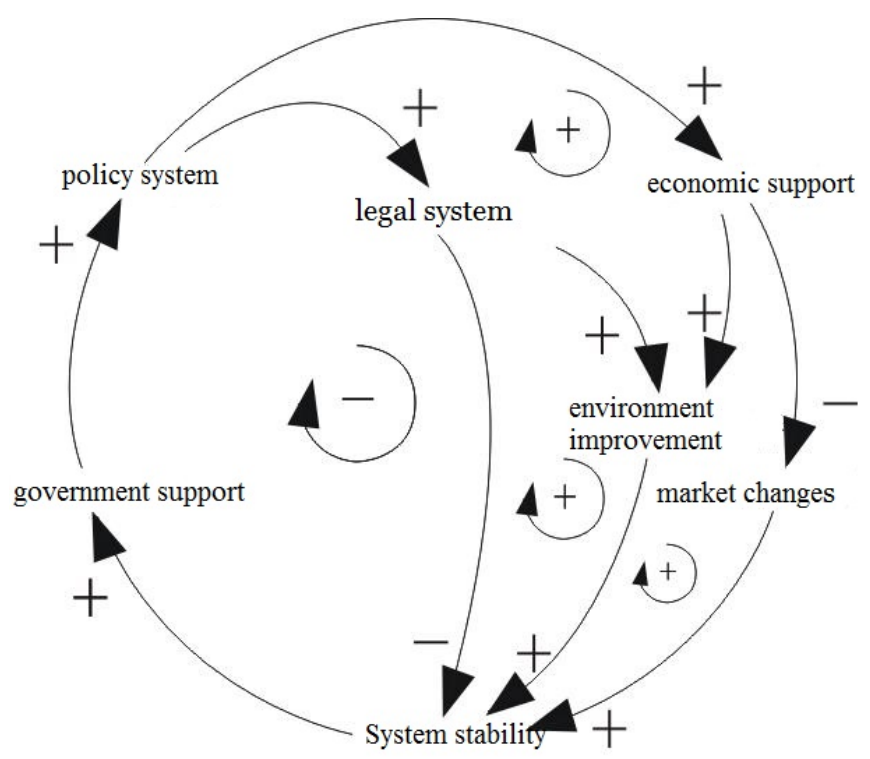

Figure 8. Mechanism of industrial ecosystem stability and its influence factors in environmental subsystem

ecosystem and its four sub systems factors between the mechanism of graph, and concluded that the stability of industrial ecosystem and its influencing factors between the mechanism model, as shown in Figure 5. In order to make the model more intuitive and easy to analyze, it omitted the influence factors that only appear on one of the influencing factors.

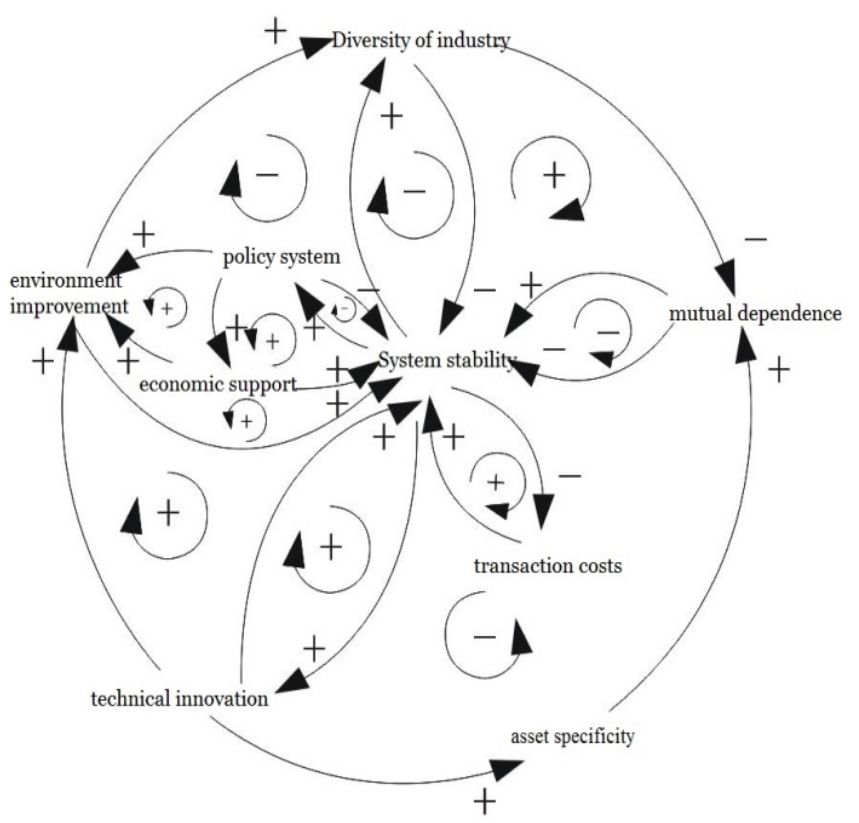

Figure 9. Mechanism of industrial ecosystem stability and its influencing factors

\section{Conclusion}

By the stability of industrial ecosystem and its influencing factors between mechanism models, we can conclude that, the interaction of all the factors in the stability of the system of the four subsystems by system and the formation of the feedback loop. The following are the system model of influence the critical path of the ecosystem stability is analyzed in detail.

(1) The social subsystem of four paths, ecological chain length, industry diversity, inter dependence degree, key enterprises, members of the distance, communication barriers etc. effects of industrial ecosystem stability factors and key enterprises strength is closely related to, and geographical location and more is mainly affected by the influence of system stability. Therefore, the enhancement of the comprehensive strength of the key enterprises is to enhance the stability of the system is the key link. In addition to enhancing the economic strength, the key enterprises should pay special attention to the construction of ecological enterprise culture, and establish a green image.

(2) In the 3 path of the resource subsystem, technological innovation is the source of system stability, so it is the key link to the stability of the industrial ecosystem. For the system of enterprise to increase the reuse technology development investment of by-products and waste of resources, speeding up the pace of reform of related technologies; for the government to concentrate on support a number of key industries, key enterprise resource conservation and comprehensive utilization of technological transformation projects, incentive related technology between enterprises with low cost and fast diffusion, the adjustment of industrial structure and promoting clean production technology closely, and gradually establish a perfect green technology support system.

(3) In the 3 path of the environmental subsystem, the government support is the source of the system stability, so the government support is very important to create a stable environment for the development of the industrial ecosystem. At present, some existing systems and macro industrial policies still serve the traditional economic development model, which has become the restrictive factor of the stable development of the industrial ecosystem. Relevant government departments should actively to abolish the revision of these institutions and policies, constructed as soon as possible to improve the development of ecological industry policies and regulations system, and improve the regulatory mechanism, increase policy enforcement, to ensure that policy has been implemented in an all-round way.

(4) In the 3 path of the economic subsystem, the transaction cost is the only direct influence factor of the system stability, so it is one of the important ways to reduce the transaction cost. Transaction cost is from under the influence of the human factors and environment factors interaction arising from the phenomenon of market failure, so perfect credit punishment mechanism and symmetric information environment can reduce to an exchange to pay the transaction cost. 


\section{Acknowledgements}

Researches in this paper were supported by Civil Aviation University of China Research Foundation (2015QD06S); Central University Fund (ZXH2012L004).

\section{References}

[1] Anastasia, T. (2012). Business models for industrial ecosystems: a modular approach. Journal of Cleaner Production, 29, 246-254.

[2] Bruce, T., Paul, D. (2014). Toward an infinitely reusable, recyclable, and renewable industrial ecosystem.Journal of Cleaner Production, 66, 392-406

[3] Cathryn, C.,Selina, A. (2015). Cumulative effects of planned industrial development and climate change on marine ecosystems. Global Ecology and Conservation, 4, 110-116.

[4] Changhao, L., Chunyuan, M. (2012). Going beyond the sectoral boundary: a key stage in the development of a regional industrial ecosystem, Journal of Cleaner Production, 22, 42-49.

[5] Crespo, P., Santos, V. (2015). Construction of Integrated Business Management Systems for Micro and Small Enterprises.RISTI-Revistalbérica de Sistemas e Tecnologias de Informação, (15) 35-49.

[6] Michael, H. (2015). Greater Boston×s industrial ecosystem: A manufactory of sectors. Technovation, 39, 4-13.

[7] Pereira, C., Ferreira, C. (2015). Identification of IT Value Management Practices and Resources in COBIT 5.RISTIRevistalbérica de Sistemas e Tecnologias de Informação, (15) 17-33.

[8] Zhang, K. (2016). Planning regional ecosystem sustainability under multiple uncertainties-An interval stochastic credibility-constrained programming approach, Ecological Indicators, 70, 134-150. 